\title{
TECNOLOGIAS DIGITAIS E INOVAÇÃO EM PROJETOS DE EXTENSÃO DA UNICARIOCA COM INICIAÇÃO CIENTÍFICA EM CONTEXTOS DE EMPREENDEDORISMO POPULAR
}

\author{
DIGITAL TECHNOLOGIES AND INNOVATION IN \\ UNICARIOCAEXTENSION WITH SCIENTIFIC INITIATION \\ IN CONTEXTS OF POPULARENTREPRENEURSHIP
}

\author{
Alexandre Fernandes Ferreira \\ Professor da Graduação em Administração da UniCarioca \\ ORCID: https://orcid.org/0000-0002-7828-8265 \\ Fabiana Adão \\ Professora da graduação em Administração da UniCarioca \\ ORCID: https://orcid.org/0000-0003-1101-3862 \\ José Otávio da Silva \\ Professor da graduação em Administração da UniCarioca \\ ORCID: https://orcid.org/0000-0001-5280-9571 \\ Nair Martins de Sá Santos \\ Professora da graduação em Administração da UniCarioca \\ ORCID: https://orcid.org/0000-0002-7041-2153 \\ Cesar Felipe de Brito Rezende \\ Aluno da UniCarioca do curso de Comunicação \\ ORCID: https://orcid.org/0000-0003-4403-669X \\ Lucas Bernardo da Cunha \\ Aluno da UniCarioca do curso de Marketing \\ ORCID: https://orcid.org/0000-0002-3938-6620 \\ Luiz Fernando Silva da Silveira \\ Aluno da UniCarioca do curso de Ciência da Computação \\ ORCID: https://orcid.org/0000-0002-3986-8363 \\ Rafael de Morais Sayão Lima \\ Aluno da UniCarioca do curso de Engenharia Civil \\ ORCID: https://orcid.org/0000-0002-4375-3948 \\ Vinicius Lima \\ Aluno da UniCarioca do curso de Administração \\ ORCID: https://orcid.org/0000-0003-1956-0940 \\ Tatiana de Paula de Oliveira \\ Aluna da UniCarioca do curso de Engenharia de Produção \\ ORCID: http://orcid.org/0000-0002-4084-7893
}




\section{RESUMO}

O novo paradigma econômico e social tem como característica o novo individualismo, que simboliza o faça por você mesmo, caracterizando-se por uma necessidade vital de construir redes de vizinhança e parcerias para sobreviver ao faça sozinho. É preciso aprender a lidar com as variáveis insurgentes: desemprego, terceirização, aprendizado constante e incessante. Se quem tem recursos enfrenta estes novos paradigmas com dificuldades, imagine-se quem está alijado dos frutos do bem-estar social. É sobre este tema que envolve trabalho, parcerias, inclusão e exclusão que se debruçou este projeto de Extensão com alunos e professores da Iniciação Científica da UniCarioca para formar empreendedores populares moradores da Favela da Rocinha,

Palavras-Chave: Iniciação Científica. Projeto de Extensão. Empreendedorismo Popular. Inovação. Inclusão.

\section{ABSTRACT}

The new economic and social paradigm is characterized by the new individualism, which symbolizes doing it for yourself, characterized by a vital need to build neighborhood networks and partnerships to survive doing it alone. We must learn to deal with the insurgent variables: unemployment, outsourcing, constant and incessant learning. If those who have the resources face these new paradigms with difficulties, imagine who is deprived of the fruits of social well-being. It is on this theme that involves work, partnerships, inclusion and exclusion that this Extension project has dealt with students and professors of the UniCarioca Scientific Initiation to form popular entrepreneurs.

KeyWords: Scientific Initiation. Extension Project. Popular Entrepreneurship, Innovation. Inclusion.

\section{INTRODUÇÃO}

O problema que se investigou neste projeto diz respeito à seguinte questão: “ De que forma a universidade pode utilizar as tecnologias digitais para ofertar projetos de extensão de empreendedorismo popular, para ensinar ferramentas de trabalho para grupos excluídos? A metodologia utilizada considerou um modelo peer-to-peer (P2P) entre alunos e professores como pesquisadores associados na coordenação conjunta da Iniciação Científica. Foi um modelo de aprendizado para todos e possibilitou a aquisição de um conhecimento valioso para os participantes.

Cabe ressaltar, neste momento, que as justificativas para este estudo não se referem apenas à necessidade de visão empreendedora e inovação para compreender ou desenhar novos formatos organizacionais, mas também se referem à percepção de que nosso ser está em transformação nesta avalanche que instala o futuro e que precisaremos escolher nossas identidades e reconstruir nossas subjetividades, para que possamos participar deste jogo social pós-moderno, intemporal e sem limites. A Iniciação Científica neste projeto partiu deste princípio de que é possível reconstruir subjetividades e identidades através do estudo e do trabalho.

Este grupo de professores e alunos que se juntou neste projeto de Extensão acredita que os novos paradigmas econômicos e sociais podem ser vividos sem perder a colaboração, a humanização, a solidariedade, a compaixão. Estes serão ingredientes 
fundamentais e de destaque no mundo do trabalho, pois significa o aprender fazendo. Foi isto que ensinamos aos nossos alunos, na medida que como professores íamos aprendendo também. Daí a importância deste projeto de Extensão de Iniciação Científica em Empreendedorismo Popular.

\section{REFERENCIAL TEÓRICO}

Alguns dados são importantes para iniciar esta discussão.

Percentual de domicílios com telefone e microcomputador por classe de rendimento mensal familiar - PNAD 2015

\begin{tabular}{l|l|l|l|c}
\hline Mínimo & Total & Até 10 & $\mathbf{1 0}$ a 20 & Mais de 20 \\
\hline Telefone Fixo & $35,3 \%$ & $31,8 \%$ & $75,6 \%$ & $83,0 \%$ \\
\hline Telefone Celular & $91,2 \%$ & $90,6 \%$ & $99,4 \%$ & $99,4 \%$ \\
\hline Telefone (Fixo ou Celular) & $93,5 \%$ & $92,8, \%$ & $99,9 \%$ & $99,9 \%$ \\
\hline Telefone Fixo e Celular & $33,2 \%$ & $29,5 \%$ & $75,0 \%$ & $82,5 \%$ \\
\hline Só Telefone Fixo & $2,1 \%$ & $2,3 \%$ & $0,6 \%$ & $0,5 \%$ \\
\hline Só Celular & $58,0 \%$ & $61,1 \%$ & $24,4 \%$ & $16,9 \%$ \\
\hline Microcomputador & $46,2 \%$ & $42,3 \%$ & $5,6 \%$ & $96,0 \%$ \\
\hline Micro com acesso à Internet & $40,5 \%$ & $36,4 \%$ & $92,0 \%$ & $94,4 \%$ \\
\hline
\end{tabular}

O Comitê Gestor da Informática no Brasil - TIC Domicílio confirma os dados da PNAD de 2015.

CGI - TIC DOMICÍLIO (2017) : Os internautas brasileiros podem ser diferenciados em quatro grupos de competências digitais: (i) instrumentais; (ii) interativas; (iii) limitadas; e (iv) amplas, com maior concentração no grupo de habilidades limitadas. Os integrantes do grupo de habilidade instrumental caracterizam-se por possuírem maiores níveis de habilidades relacionadas às atividades de busca de informação e educação e trabalho, atividades essas de maior capitalenhacing. Eles tendem a acessar a Internet por meio de diversos dispositivos (desktops, laptops e celulares), são majoritariamente do sexo feminino, pertencentes a classes sociais de maior nível educacional e com idade variando entre 16 e 44 anos. Em linhas gerais, os resultados sugerem que os integrantes desse grupo utilizam a Internet como ferramenta para fins pessoais, profissionais e educacionais. Os usuários do grupo de habilidades interativas se caracterizam por terem maiores níveis de habilidades de criação de conteúdo e multimídia. Os membros desse grupo tendem a pertencer a uma faixa etária mais jovem (entre 10 a 24 anos), utilizam Internet preferencialmente do celular, além de serem majoritariamente das classes $C$ e DE e do sexo masculino. Os usuários do grupo amplo apresentam o maior nível de habilidade digital em todos os seis 
domínios analisados, enquanto que os usuários limitados possuem o perfil oposto, isto é, menor nível de habilidade digital. Em ambos os grupos, a classe social é o principal fator de discriminação, no qual membros das classes C e DE (de menor instrução) tendem a apresentar perfil de habilidades restritas e limitadas, enquanto membros das classes $A B$ tendem a ter habilidades digitais amplas. Os achados desta investigação contribuem para uma maior compreensão do fenômeno da exclusão digital no Brasil, principalmente no que tange a evidenciação das desigualdades nos níveis de competências digitais e caracterização de uma tipologia de habilidades do internauta (ARAUJO; REINHARDT, 2017).

Tudo é difícil para quem vive em comunidades em situação de exclusão do bemestar social. Conectar-se à Internet e também deslocar-se é uma tarefa complexa, que exige estar trabalhando. Conexão, trabalho e redes de apoio são variáveis importantes na vida dessas pessoas. Estudar este modelo produtivo solidário destaca as relações entre agentes de desenvolvimento, sendo que, dentre eles, participam a universidade e o Estado na criação conjunta da identidade do trabalho desse grupo.

Nos trabalhos desenvolvidos por esse grupo se insere um processo longo e intermitente de adoção de novas tecnologias computacionais. Certamente, o grupo precisa dominar todo um conjunto de conhecimentos que inclui a Internet e vai além, e que se aprende nas parcerias com outros agentes, como a universidade. Temos a consciência de que fizemos uma pequena parte. Eles são moradores de favela, grupos vulneráveis pela precarização do trabalho, proximidade com o tráfico de drogas, sem acesso a muitos bens da sociedade. Há uma relação de convivência com a insegurança pública, nem sempre muito saudável, e isto tem uma representatividade quando se quer analisar os efeitos adversos da exclusão do bem-estar social e dos frutos da aquisição do conhecimento.

A ausência de oportunidades de trabalho em larga escala alimenta e estimula a desigualdade social. Com os impactos causados pelas inovações tecnológicas, as transformações no mercado de trabalho, a internacionalização da economia e o desemprego estrutural, entre outros pontos, países da América Latina sofrem de forma mais acentuada os efeitos de uma estrutura que acentua as desigualdades. A distância social entre favela e asfalto no Rio é cinco vezes maior do que a proximidade física faz parecer.

A experiência que está sendo vivida mobiliza para o aprendizado do empreendedorismo, da inovação e de novas tecnologias.

Pode-se dizer que estamos falando de três níveis de aprendizado: individual, coletivo e organizacional. O primeiro remete a cada um dentro do projeto; o segundo considera as experiências e as crenças que se socializam entre eles - está no nível da comunidade -, e o terceiro é o contato com o mundo, o processo que simboliza o renascimento do trabalho em novos patamares. Os três níveis atuam uns sobre os outros.

Eles não viveram só um programa de métodos e tecnologia, mas, de forma conjunta, aprenderam o quanto a criatividade no trabalho e a cidadania estão hoje ligadas ao empreendedorismo no desafio da criação do empreendedorismo popular. 


\subsection{Coleta de dados coletados na pesquisa preliminar de análise de campo}

Pergunta 01 - Qual o seu nome?

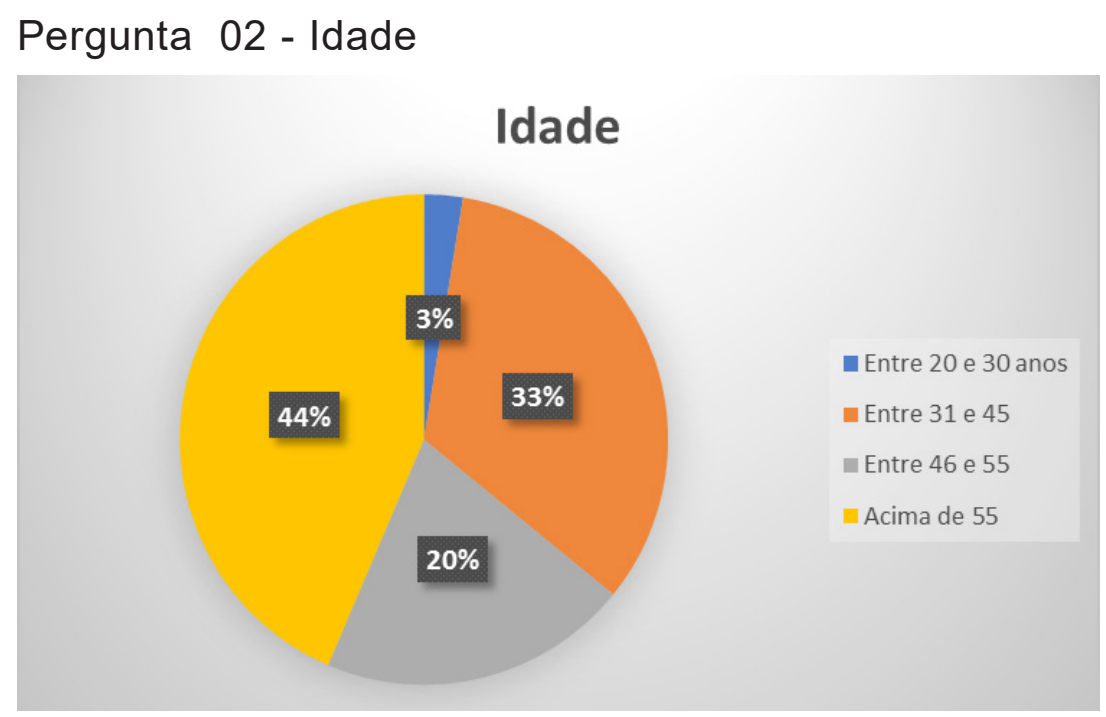

Fonte: Dados da pesquisa (2019)

Este é um dado muito importante: $44 \%$ dos empreendedores estão numa faixa etária acima de 55 anos. O que será que este dado nos diz, como transformá-lo em informação, para que se possa agir sobre ele?

$\mathrm{Na}$ verdade, o que se percebe é que as pessoas estão ingressando neste mercado de vendas empreendedoras a partir de 55 anos. Outro fato é que o trabalho na vida destas pessoas começa mais tarde, porque lhes falta muitas vezes treinamento e onde buscá-lo, e isso se reflete na ausência de oportunidades no mercado de trabalho.

É bom lembrar que estas entrevistas foram obtidas na UniCarioca com empreendedores da Rocinha, num projeto de parceria com a Prefeitura do Rio de Janeiro.

Um dado é interessante: nota-se, no gráfico, que 33\% dos empreendedores têm entre 31 e 45 anos, o que denota que há um efeito importante que leva pessoas mais jovens a buscarem se conectar com o Mercado como empreendedores. Talvez isso seja um reflexo de programas sociais como o Prouni e outros projetos de políticas públicas de educação e trabalho.

As parcerias são fundamentais para lidar com o conhecimento e com o aprendizado de novos métodos e novas tecnologias:

Somente na convivência com outros, o homem é homem (sic), tanto para Platão como para Aristóteles, a quem pareceu natural a sua existência na comunidade, ou polis, dado que a verdadeira natureza humana só nela pode ser plenamente realizada.

Não existem caminhos prontos, e é fundamental que a informação possa atualizar e articular o conhecimento local, sem descaracterizá-lo, transformando-se em conhecimento. 


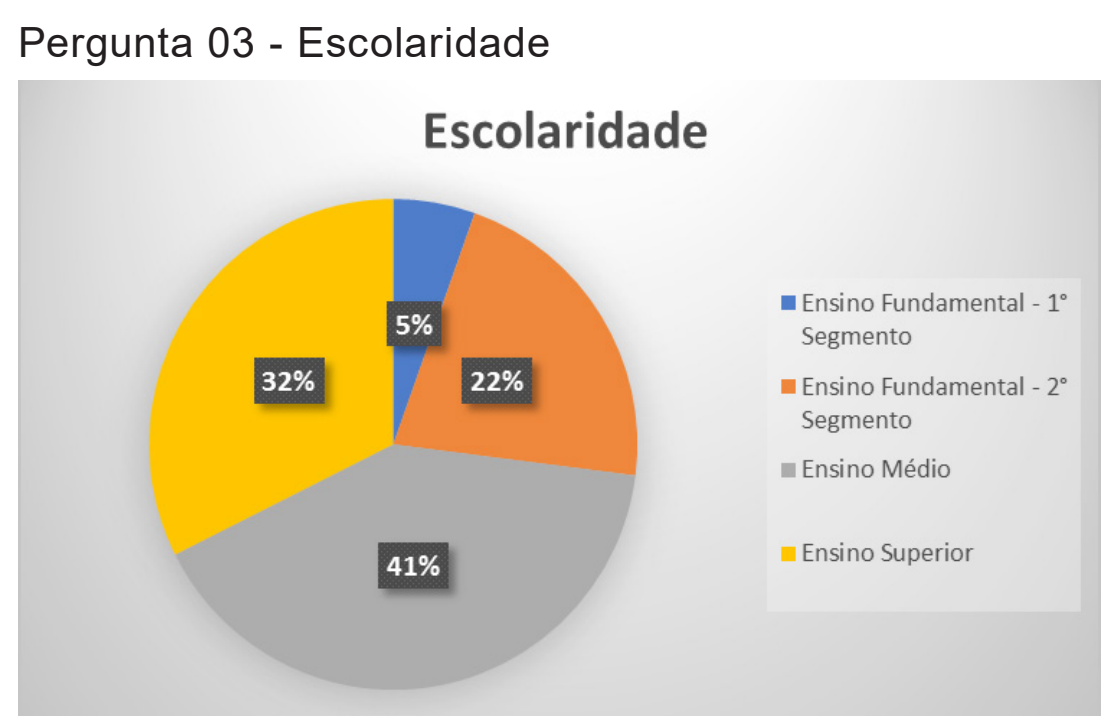

Fonte: Dados da pesquisa (2019)

Que dados interessantes mostram estes gráficos: $32 \%$ têm ensino superior, $41 \%$, ensino médio, e $44 \%$ têm idade acima de 55 anos. São dados importantes que nos dizem que o Estado, de alguma forma, vem preenchendo certas lacunas da educação, quanto ao ensino médio. Agora a inserção no campo do trabalho para geração de trabalho e renda depende ainda fortemente de projetos de parceria, no qual a universidade é um dos agentes.

Este projeto é uma parceria entre a Prefeitura do Rio de Janeiro, a UniCarioca e empreendedores da Rocinha. Professores da UniCarioca estão envolvidos, ministrando cursos de empreendedorismo e ensinando a fazer um Plano de Negócios.

O caminho é longo, não se tiram estas diferenças da noite para o dia. E estes números não são só quantitativos; eles revelam, na análise dos dados tabulados, uma vida conjunta, as mesmas dificuldades, os mesmos sonhos. Também devem ser comparados com os dados da PNAD 2015, que mostra que essas pessoas estão desconectadas do mundo virtual, o que denota que terão dificuldades em vender seus produtos pela Internet, através de um site pessoal.

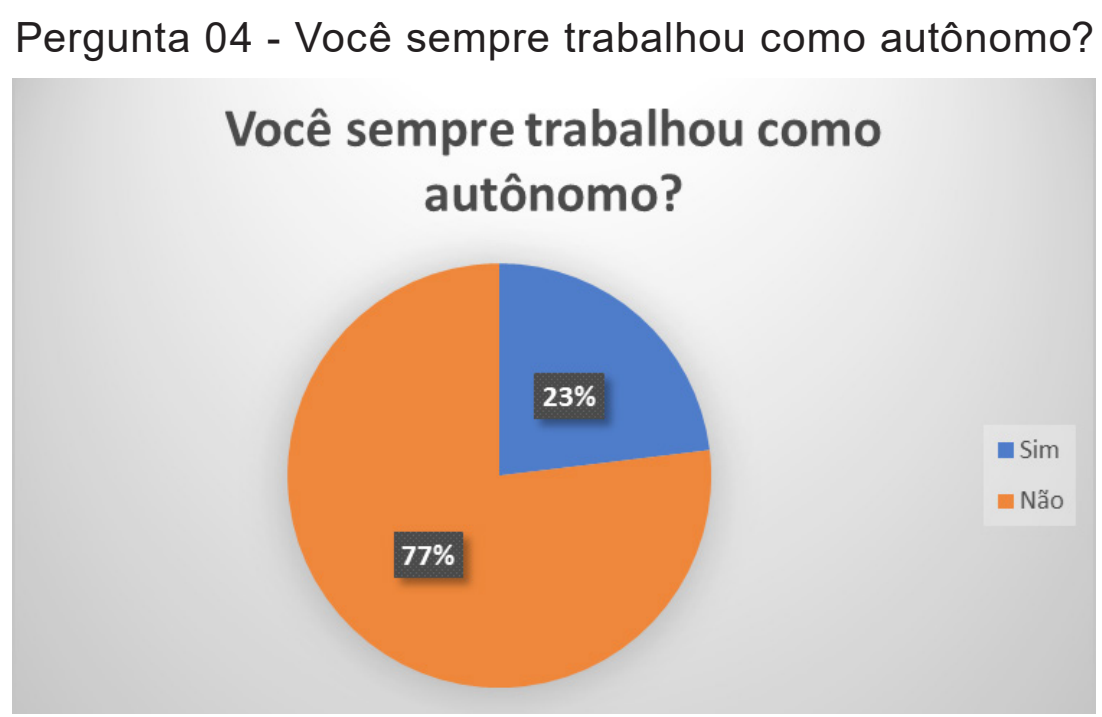

Fonte: Dados da pesquisa (2019) 
77 \% estão pela primeira vez participando de projetos em parceria para inclusão no mundo do trabalho. Isto significa que há um campo aberto a parcerias nestas comunidades em situação de exclusão do bem-estar social. Este dado se torna uma informação quando se percebe que é um dado representativo de um grupo que vive na Rocinha e que experimenta uma vida semelhante.

$O$ dado se transforma em informação e nota-se que a participação em nível coletivo fortalece os laços comunitários:

Estas pessoas precisam de treinamento em muitas disciplinas, nas mais diversas áreas, para que haja uma sedimentação nas lacunas de conhecimento; mas, juntos, eles podem acionar instituições e fazer parcerias.

A participação comunitária consiste num microcosmo político-social suficientemente complexo e dinâmico de forma a representar a própria sociedade ou nação. Quer dizer que a participação das pessoas em nível de sua comunidade é a melhor preparação para a sua participação como cidadãos em nível de sociedade global.

Pergunta 05: O que o estimulou a abrir seu próprio empreendimento?

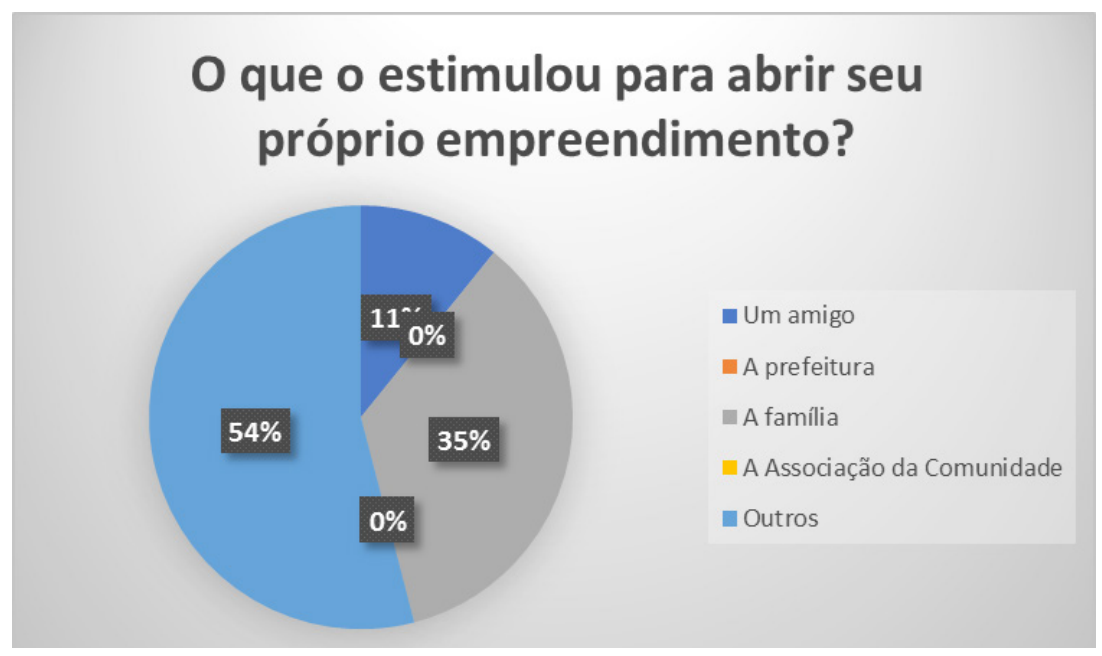

Fonte: Dados da pesquisa (2019)

Há em torno destes indivíduos um "Ambiente de Informação" que pressupõe a pessoa inserida no mundo, interagindo e construindo a informação, a partir do local onde vive, mas lançando pontes sobre a vida a sua volta. Pelo gráfico, pode-se afirmar que embora este projeto seja uma parceria com a Prefeitura e a UniCarioca, para chegarem até aqui outras pontes foram usadas por estas pessoas. A família teve o seu papel incentivador, mas a criatividade e o desejo de inovar e aprender foram os principais mobilizadores desta etapa da vida dessas pessoas.

Esta dimensão interna do indivíduo, em sua comunidade, conectando-se com outras comunidades, outras pessoas, outros ambientes, Internet inclusive, tudo isso mobiliza o conhecimento tácito de cada um e traz à tona um novo processo de aprendizado, com cidadania, que considera a história de cada um, e os insere no campo da linguagem, em contato com outras pessoas, com vivências semelhantes, despertando o que está escondido.

A linguagem da qual se trata aqui, repitamos, não é o objeto que os linguistas estudam, nem algum veículo neutro próprio para transmitir as mensagens eficazmente. Uma linguagem é a condição de possibilidade de um mundo, desdobra o campo de significado donde 
surgem os eventos, estende a grande placa imaginária sobre a qual os fatos se desenrolam e encadeiam (MATURANA, 1998).

Pergunta 06: Quais são os seus clientes

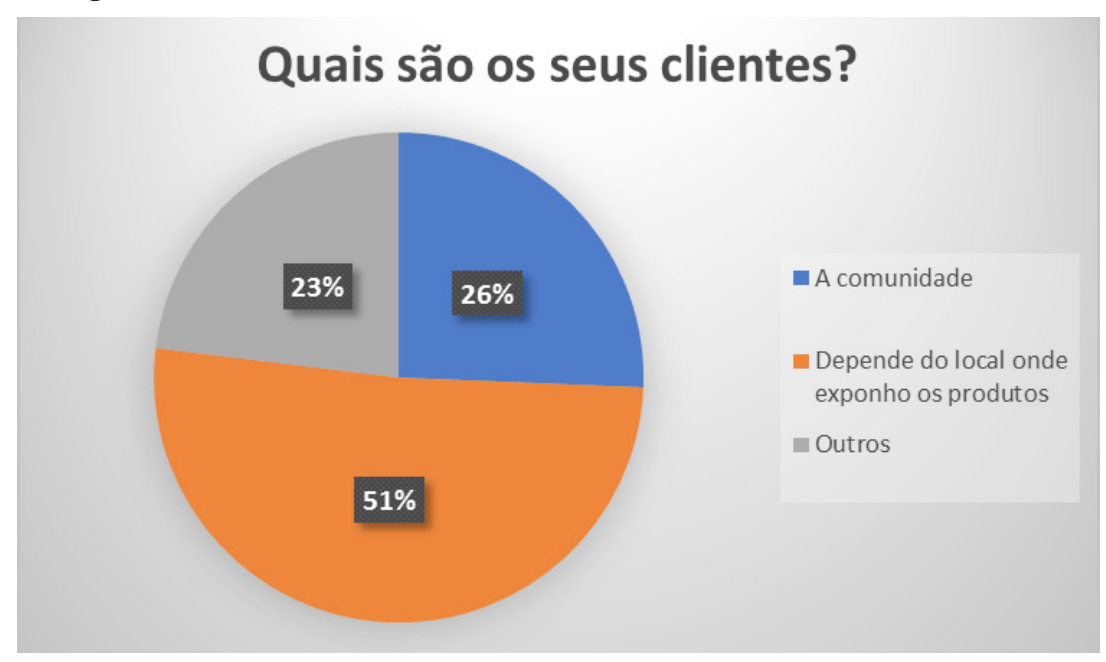

Fonte: Dados da pesquisa (2019)

Estas pessoas estão alijadas há tempos de uma história coletiva e estão buscando encontrar juntas suas próprias soluções, reinventarem vidas, protagonizarem histórias, compartilhando práticas e conhecimento para produzirem novos conteúdos, para empreenderem trabalho e renda.

Este percentual de $51 \%$ não é vazio, nem apenas um número técnico. Significa que a maioria do grupo está buscando oportunidades de apresentar os seus produtos, está buscando locais de exposição dos seus trabalhos. Levando em consideração a narrativa de suas vidas coletivas, pode-se afirmar que a cooperação e solidariedade são instrumentos da vida coletiva comunitária e que estão empregando estas ferramentas sociais para solidificarem esta etapa do empreendimento. Mas não têm Internet disponível. Tudo é difícil.

CGI - TIC DOMICÍLIO (2017): Os dividendos das tecnologias digitais só podem ser plenamente alcançados quando toda a sociedade tiver acesso a seus recursos. Portanto, um dos principais desafios que os formuladores de políticas públicas devem enfrentar é a distribuição mais equânime de infraestruturas de acesso à Internet. (...) Abordagens intramunicipais para alocação de recursos escassos revelam-se um dos desafios mais complexos para o administrador público brasileiro, mas, uma vez superado, ele poderia mitigar riscos de alocações indevidas de recursos públicos em regiões não prioritárias ou com baixo retorno social. Esforços para melhorar essa sistemática de mapeamento de regiões prioritárias e alocação de recursos são necessários e certamente o órgão regulador dispõe dos meios para aprimorar esse levantamento. Em qualquer cenário, o prejuízo de não se disponibilizar a infraestrutura se sobrepõe, em qualquer contexto, à inércia para alocação do recurso. Essa percepção deve guiar o tomador de decisão sob o risco de ampliar o hiato de acesso à banda larga no país (CHARLITA DE FREITAS et al.). 
Pergunta 07: Quais são os seus conhecimentos em informática

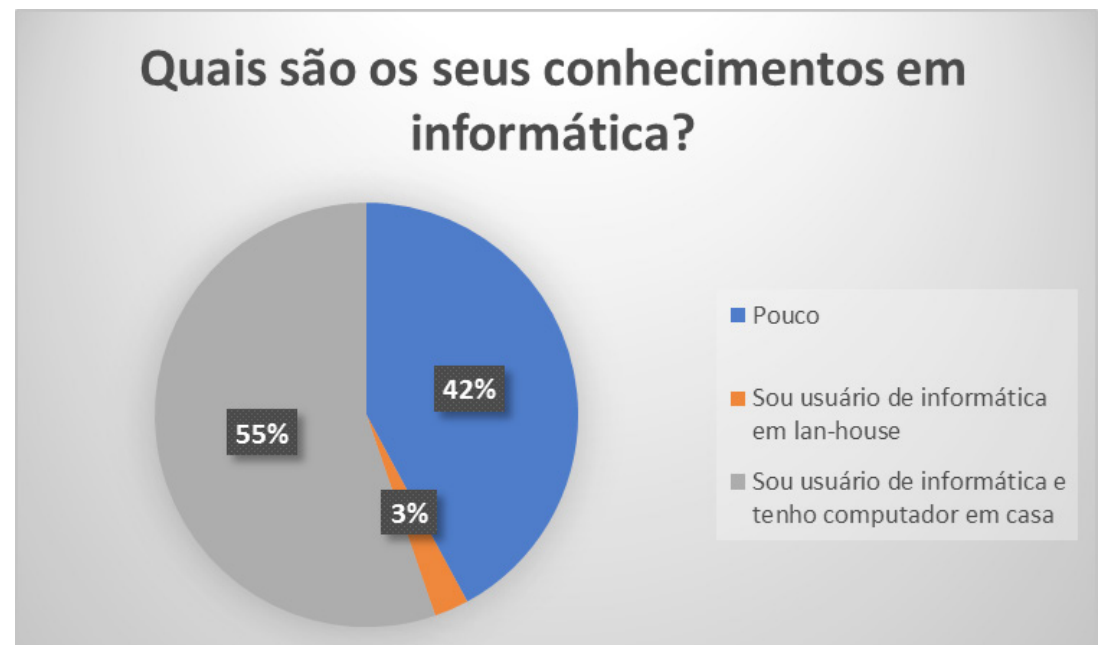

Fonte: Dados da pesquisa (2019)

$55 \%$ usam informática de casa. Este dado é interessante, se pensarmos em Educação à Distância. No entanto, temos que extrair informação deste dado. Pela observação, durante todo o processo da pesquisa pode-se perceber que eles possuem computador, mas a Rede é instável, o trabalho é instável, as finanças são instáveis, o que denota uma desconexão com o mundo virtual, mesmo que usem a informática. Pode-se afirmar que não possuem o letramento em alta tecnologia de informática, que o mundo virtual exige.

Pode-se definir que ao usar alta tecnologia, desenvolve-se uma nova forma de pensar o mundo, o trabalho e o próprio existir como pessoa, partilhando esquemas de interpretação do mundo. Na realidade, é fundamental reconhecer que:

O verdadeiro drama da pobreza não é apenas o peso das privações materiais, mas também a ausência da possibilidade real de escolher um outro modo de vida. AEducação tem como meta o desenvolvimento do potencial humano.

Estas pessoas ao usarem a Internet pelo celular ou de forma precária pelo computador estão aprendendo questões de trabalho. A partir desta vida social vem à luz a cidadania com as pessoas trocando pontos de vista sobre questões de importância ao bem comum.

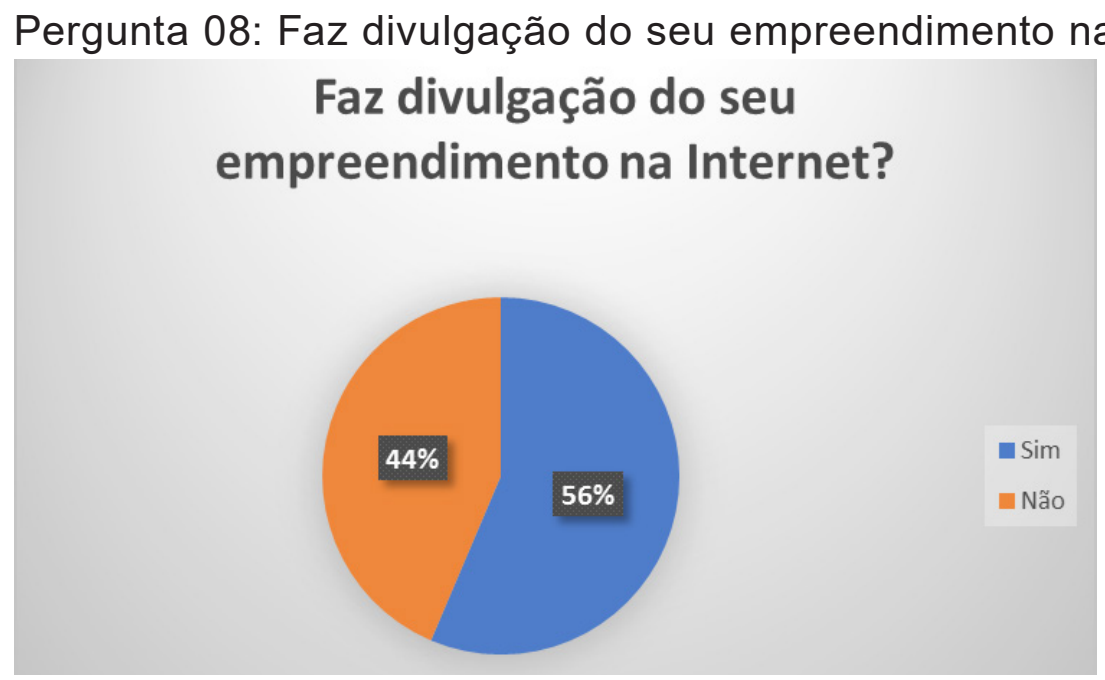

Fonte: Dados da pesquisa (2019) 
Este dado é importante, pois se nota que a maioria destas pessoas está em fase de letramento, ou seja, está em contato com outras pessoas, com o Poder Público, com outras instituições, desenvolvendo socialização e cidadania através da Internet.

\begin{abstract}
CGI - TIC DOMICÍLIO (2017) : Com a expansão do uso da Internet a partir dos anos 2000 - principalmente nos países desenvolvidos -, verificou-se que a simples superação da barreira do acesso às TIC não era suficiente para acabar com esse tipo exclusão (Van Dijk \& Hacker, 2003; Van Dijk, 2005). Nesse sentido, as investigações desse campo buscaram explorar outras dimensões inerentes ao referido fenômeno, contemplando questões relacionadas tanto às competências e habilidades digitais no uso das TIC, quanto ao comportamento, atitudes e motivação do usuário que utiliza o artefato tecnológico. Tal corrente de estudos é conhecida por explorar os efeitos da exclusão digital de segunda ordem (HARGITTAI, 2002; DEWAN; RIGGINS, 2005 apud ARAUJO; REINHARDT, 2017).
\end{abstract}

Pergunta 09: Você lê jornais, revistas ou livros?

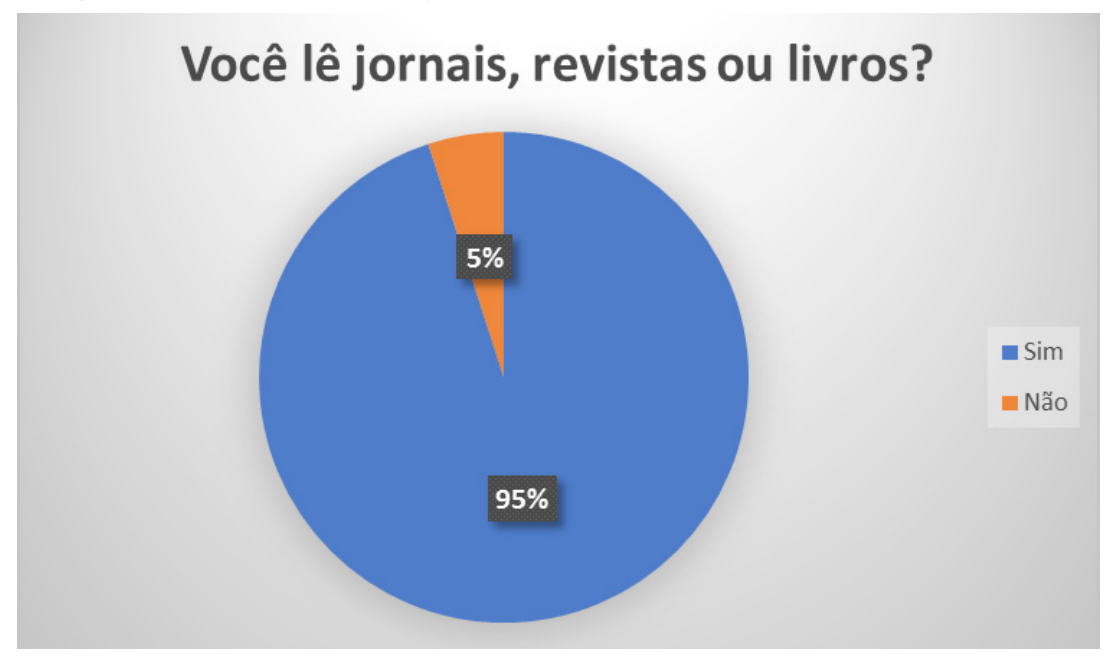

Fonte: Dados da pesquisa (2019)

Hoje se vê a comunidade engajada em participar de projetos coletivos para superar a pobreza. Um contraponto deste empoderamento de grupos excluídos corresponde ao aprendizado do uso da Internet.

Pergunta 10: Quais os seus hábitos de lazer?

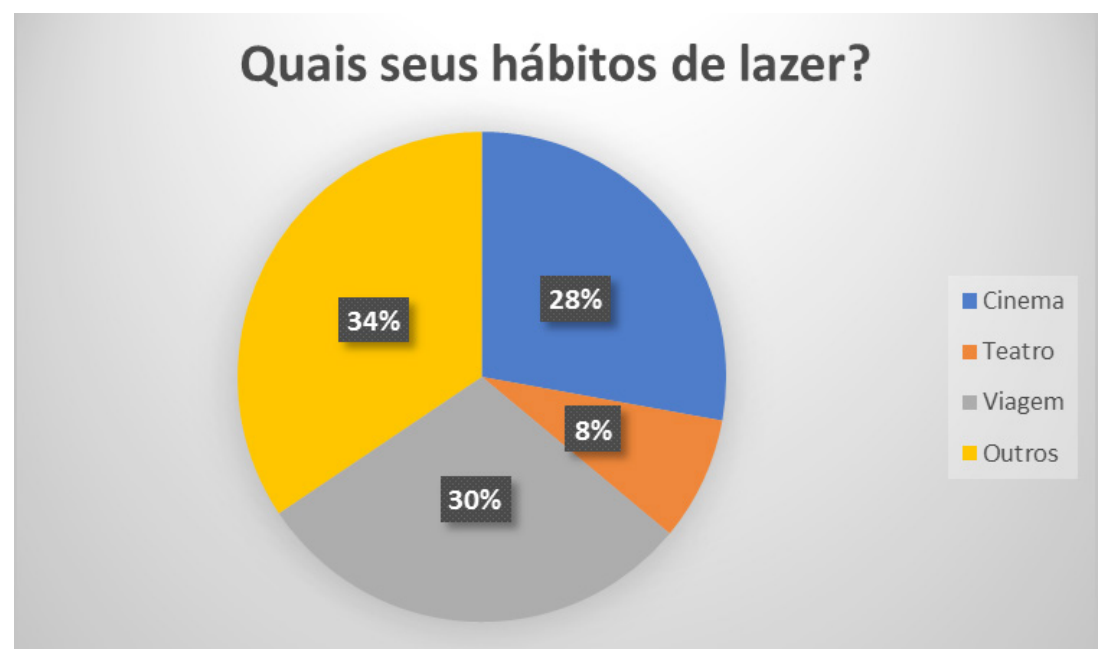

Fonte: Dados da pesquisa (2019) 
Viagem, cinema e outros, como jogos, internet, leitura, dança etc. são fontes de conhecimento, e aqui se evidencia o sujeito que aprende na troca de ideias, de experiências, não só em sua comunidade, em seu ciclo familiar, mas interagindo no mundo. Isto indica uma nova possibilidade de construção da informação, com uma interação social mais dinâmica.

No lazer, os indivíduos podem transformar ou reforçar seu ponto de vista e desenvolver uma visão crítica da vida.

Segundo Moraes (1999), no exercício do livre-arbítrio se depreende que quem não tem acesso à informação não constrói questões, não pode compartilhar ideias, não tem conhecimento, não tem informação para decidir, não tem alternativas. Não tem liberdade de escolha. Não tem liberdade. Aqui, informação, livre arbítrio e lazer estão conectados.

Num efeito recursivo, a partir do lazer, há um aprendizado e compartilhamento de ideias e práticas, e os indivíduos vão, ao mesmo tempo que enfrentam as escolhas, aprendendo novas práticas, o que também permite aprender e socializar os novos valores. Lazer e valores talvez estejam mais conectados do que conseguimos enxergar.

\subsubsection{As tecnologias digitais neste contexto de educação não formal do grupo}

Todo o processo pedagógico de formação dos empreendedores da Rocinha foi conduzido através do AVA - Ambiente Virtual de Aprendizagem da UniCarioca, de forma conjunta com professores e alunos, que hoje apresentam este artigo. Os materiais eram postados no AVA, e todos os professores e alunos tinham acesso ao seu conteúdo e ministravam e participavam dos seminários que ocorreram na UniCarioca, de formação em empreendedorismo popular. Alguns professores utilizaram - Centro Municipal Rinaldo de Lamare, na Rocinha, para ministrar seminários. O objetivo deste trabalho pedagógico era que cada um doa empreendedores da Rocinha aprendesse e fizesse o plano de negócios.

Este espaço novo e virtual de colaboração entre professores e alunos através de uma tecnologia digital simbolizou, nas reuniões, nas salas de aula, nos encontros, um espaço invisível de conhecimentos, saberes, pensamentos, que ainda não se fixaram, mas que brotam e tendem a se transformar em novas maneiras de viver, novas formas de empreender e novos modos de constituir-se como empreendedor ou professor em sociedade. Tudo é lento e leva tempo, afinal são diferenças históricas enraizadas que estamos buscando superar, ao empreenderem estas parcerias.

Neste cenário, destacam-se as relações entre agentes de desenvolvimento, sendo um deles a universidade e toda esta rede pode convergir para ampliar a criação conjunta da identidade do trabalho deste grupo. A adoção de tecnologias pode ajudar na tarefa de melhor administrar o trabalho, mas é preciso que haja políticas públicas de democratização de redes de Internet.

\section{METODOLOGIA}

A metodologia empregada neste projeto considerou uma estratégia de coleta e análise de dados com base na norma 510 da Secretaria de Saúde e do Comitê Nacional de Ética em Pesquisa. O referencial teórico buscou embasar as discussões aqui apresentadas. 
Considerou-se durante todo o trabalho um modelo P2P entre alunos e professores como pesquisadores associados na coordenação conjunta da Iniciação Científica. Os empreendedores da Rocinha que participaram deste projeto de Extensão da Iniciação Científica estavam participando da formação em empreendedorismo ministrada pelos agentes da Prefeitura do Rio de Janeiro. Nós, professores e alunos da UniCarioca, nos juntamos em parceria ao Núcleo de Produção Inclusiva da Prefeitura do Rio de Janeiro, para formar nas habilidades e competências acadêmicas de Empreendedorismo este grupo de moradores da Rocinha, em treinamento na Prefeitura do Rio de Janeiro.

O experimento P2P se desenvolveu a partir do uso dos recursos das tecnologias digitais do Ambiente Virtual de Aprendizagem da UniCarioca e consolidou-se na colaboração entre professores e alunos de Iniciação Científica do Curso de Administração, em projeto de Extensão em empreendedorismo popular, na troca de materiais para dar conta desta pedagogia social. Este tipo de experiência vivida por alunos e professores tem um lugar privilegiado hoje no mercado de trabalho, valorizando os curriculuns de todos os envolvidos. Este projeto gerou este artigo e certamente outros virão.

Foi realizada uma pesquisa preliminar de campo com os empreendedores durante o Seminário que ocorreu no Centro Universitário Unicarioca e no Centro Municipal Rinaldo de Lamare, na Rocinha. Durante o seminário, foram realizadas entrevistas pelos alunos da UniCarioca, que, sob orientação, elaboraram, aplicaram, tabularam e analisaram os dados coletados. Esta pesquisa preliminar de dados, que está de acordo com a norma 510 do CONEP, foi feita para confirmar o problema a ser investigado.

Em Anexo colocamos o questionário aplicado aos empreendedores da Rocinha e como Apêndice desta artigo está o email da Direção do Núcleo de Produção Inclusiva da Prefeitura do Rio de Janeiro, agradecendo a parceria com a UniCarioca, na assessoria aos empreendedores na elaboração dos Planos de Negócios.

Esta pesquisa também se valeu das autorizações da Prefeitura do Rio de Janeiro, que desenvolve, com o público da Rocinha, um trabalho de inclusão social através do empreendedorismo. Assim, professores e alunos da UniCarioca, envolvidos neste projeto, utilizaram-se das permissões, autorizações e protocolos já concedidos à Prefeitura. Ressalte-se também que os dados aqui apresentados não são novos e são mesmo de domínio público. O que torna o trabalho inovador é a colaboração entre professores e alunos na coordenação conjunta da Iniciação Científica e o referencial teórico que se associou à pesquisa na análise dos dados coletados.

O público-alvo da pesquisa, 45 pessoas, luta, e muito, para a inserção no mundo glamoroso das vendas pela Internet, para obter um espaço no mercado de vendas próprias, mas a falta de telefone convencional, microcomputador e rede com acesso integral à Internet são variáveis de exclusão, e estas lacunas precisam ser supridas através de Políticas Públicas. Os dados foram obtidos no processo de observação e escuta e, depois, cruzados com os dados da PNAD 2015, divulgados pelo IBGE, e com os dados fornecidos, em seus relatórios, pelo Comitê Gestor da Internet no Brasil. A pesquisa confirma a importância deste projeto de parceria com a Prefeitura e a UniCarioca, mas registra uma lacuna nas políticas públicas de redes e comunicação, que dificulta uma democratização mais ampla da cidadania, do trabalho e da informação. 


\section{CONSIDERAÇÕES FINAIS}

Esta pesquisa resultou em um trabalho em equipe e verificou que não há apropriação de TI pela Comunidade da Rocinha; e o novo patamar tecnológico de comunicação e gestão dos empreendimentos confirmaram as evidências da não apropriação de alta tecnologia pelos empreendedores que participaram desta pesquisa, o que sublinha que fica deficitário um desenvolvimento local e uma sociedade da informação inclusiva. A partir de políticas públicas voltadas para a adoção de tecnologias de informação e comunicação, pode-se viabilizar a socialização de conhecimento e isto implica não somente a geração de conhecimentos, mas também de identidade.

Neste eixo da educação e identidade, o papel da universidade é fundamental para disseminar novas técnicas e métodos, promovendo o trabalho, a educação, mas não a apropriação de tecnologias de informação e comunicação por comunidades de baixa renda. Mas ressalte-se que pela sua participação confirmaram-se as evidências de que a universidade é um potente centro mobilizador de alta tecnologia para comunidades de baixa renda, bem como um agente de desenvolvimento econômico solidário.

Pode-se definir alta tecnologia como a capacidade de existir num mundo conectado, aproveitando as facilidades de comunicação e pesquisa, buscando negócios a partir do acesso a essas facilidades, o que permite uma nova forma de pensar o mundo, o trabalho e o próprio existir como pessoa, partilhando esquemas de interpretação do mundo.

O grupo pesquisado está longe de vivenciar o sentido de alta tecnologia em Informática e Redes.

Buscou-se mostrar como o desenvolvimento econômico passa pela participação efetiva da universidade, a partir de seus projetos de extensão, mas reitera-se aqui a importância de políticas públicas em democratização da comunicação e Redes em comunidades em situação de exclusão do bem-estar social, para se ampliar todo o trabalho conjunto.

\section{REFERÊNCIAS}

ARAUJO, Marcelo Henrique; REINHARD, Nicolau. Quem são os internautas brasileiros? Uma análise a partir das habilidades digitais. TIC DOMICÍLIOS. Pesquisa sobre o uso das Tecnologias de Informação e Comunicação nos domicílios brasileiros - 2017 - ICT HOUSEHOLDS Survey on the Use of Information and Communication Technologies in Brazilian Households, p. 29-40, 2017.

CHARLITA DE FREITAS, Luciano et al. Análise da alocação de recursos públicos para universalização da banda larga no Brasil. TIC DOMICÍLIOS Pesquisa sobre o uso das Tecnologias de Informação e Comunicação nos domicílios brasileiros - 2017 - ICT HOUSEHOLDS Survey on the Use of Information and Communication Technologies in Brazilian Households, p. 54.

LÉVY, Pierre. As tecnologias da inteligência: o futuro do pensamento na era da informática. Rio de Janeiro: Ed. 34, 2000.

MORAES, Regina. Construto Ambiente de Informação: Um estudo em comunidade 
de baixa renda. Orientadora: Gilda Maria Braga. 1999. 110 f. Dissertação (Mestrado em Ciência da Informação). MCT/IBICT - UFRJ/ECO. Rio de Janeiro, 1999.

Construto "ambiente de informação" em comunidade de excluídos: um estudo na interface da Ciência da Informação. In: PEREIRA, Maria de Nazareth Freitas; PINHEIRO, Lena Vania Ribeiro Pinheiro (orgs.). O Sonho de Otlet: Aventura em Tecnologia da Informação e Comunicação. Rio de Janeiro ; Brasília : MCT - Ministério da Ciência e Tecnologia ; IBICT - Instituto Brasileiro de Informação em Ciência em Tecnologia 2000. p.163 - 189.

A Construção de Ambientes de Informação e Trabalho na Recomposição das Relações Sociais e de Produçã. Revista Comunicação e Política, CEBELA - Centro Brasileiro de Estudos Latino-Americanos, v.VIII, nova série, maio/ago. 2001, p. 87-106.

SANTOS, Boaventura. SANTOS, Boaventura de S. (Org.). Produzir para viver: os caminhos da produção não capitalista. Rio de Janeiro, Civilização Brasileira, 2002.

TIC EDUCAÇÃO. ICT IN EDUCATION. Survey on the Use of Information and Communication Technologies in Brazilian Schools = Pesquisa sobre 0 uso das Tecnologias de Informação e Comunicação nas escolas brasileiras. Núcleo de Informação e Coordenação do Ponto BR Brazilian Network Information Center. 2017. Disponível em: www.cgi.br. Acesso em: 15 abr. 2019.

TIC DOMICÍLIOS. ICT HOUSEHOLDS. Survey on the Use of Information and Communication Technologies in Brazilian Households = Pesquisa sobre o uso das Tecnologias de Informação e Comunicação nos domicílios brasileiros. Comitê Gestor da Internet no Brasil Brazilian Internet Steering Committee. São Paulo, 2018. Site: Disponível em: www.cgi.br. Acesso em: 15 abr. 2019.

\section{APÊNDICE 01 - FORMULÁRIO USADO COM OS EMPREENDEDORES}

1. Qual o seu nome?

2. Idade

( ) entre 20 e 30 anos

( ) entre 31 e 45

( ) entre 46 e 55

( ) acima de 55

2. Escolaridade.

( ) ensino fundamental $-1^{\circ}$. segmento

( ) ensino fundamental $-2^{\circ}$. segmento

( ) ensino médio

( ) ensino superior 
4. Você sempre trabalhou como autônomo?
( ) $\operatorname{sim}$
( ) não

5. O que o estimulou para abrir o seu próprio empreendimento?
( ) um amigo
( ) a prefeitura
( ) a família
( ) a Associação da Comunidade
( ) Outros

6. Quais são os seus clientes?
( ) a comunidade
( ) depende do local onde exponho os produtos
( ) outros

7. Quais são seus conhecimentos em informática?

( ) pouco

( ) sou usuário de informática em Lan House

( ) sou usuário de informática e tenho computador em casa

8. Faz divulgação do seu empreendimento na Internet?
( ) $\operatorname{sim}$
( ) não

9. Você lê jornais, revistas ou livros?
( ) $\operatorname{sim}$
( ) não

10. Quais seus hábitos de lazer?
( ) cinema
( ) teatro
( ) viagem
( ) outro 


\section{ANEXO 01 - OFÍCIO DO NÚCLEO DE PRODUÇÃO INCLUSIVA DA PREFEITURA DO RIO DE JANEIRO}

De: Vania Souza <vaniasouza.smds@gmail.com>

Data: seg, 31 de jul de 2017 às 10:17

Assunto: Agradecimento

Para: Alexandre Fernandes Ferreira (afferreira@unicarioca.edu.br)

Prezado professor Alexandre,

Venho agradecer a prestimosa participação da UniCarioca no curso de empreendedorismo do Núcleo de Inclusão Produtiva nos anos de 2016 e 2017. Através dessa salutar parceria, contamos com aulas e assessorias dos professores da faculdade de administração e dos alunos master, que muito contribuíram para a aprendizagem de nosso público-alvo, usuários da política de assistência social do município do Rio de Janeiro.

Certos de contar com a valiosa contribuição dessa Universidade, aguardo contato para providenciarmos a cooperação técnica entre a Secretaria Municipal de Assistência Social e Direitos Humanos e UniCarioca.

Atenciosamente,

Vânia Souza da Silva

Direção do Núcleo de Inclusão Produtiva

Tel.:. (21) 2976-1221 / 2976-1057 